\title{
Relative Price Riddles in International Business Cycle Theory: Are Transport Costs the Explanation?*
}

\author{
Elisabetta Mazzenga \\ Universita' degli Studi di Roma "Tor Vergata", \\ Dipartimento di Economia ed Istituzioni, Rome, Italy \\ Morten O. Ravn ${ }^{\dagger}$ \\ Universitat Pompeu Fabra and the CEPR \\ Department of Economics and Business, Universitat Pompeu Fabra \\ Ramon Trias Fargas 25-27, 08005 Barcelona, Spain \\ This version, May 1998
}

\footnotetext{
*Parts of this paper were completed while the second author visited the University of Pennsylvania and he wishes to thank the Department of Economics for its hospitality. Comments from seminar participants at the University of Pennsylvania and Antonella Ianni are gratefully acknowledged. The usual disclaimer applies.

†Corresponding author
} 


\begin{abstract}
We study relative price behavior in an international business cycle model with specialization in production, in which a goods market friction is introduced through transport costs. The transport technology allows for flexible transport costs. We analyze whether this extension can account for the striking differences between theory and data as far as the moments of terms of trade and real exchange rates are concerned. We find that transport costs increase both the volatility of the terms of trade and the volatility of the real exchange rate. However, unless the transport technology is specified by a Leontief technology, transport costs do not resolve the quantitative discrepancies between theory and data. A surprising result is that transport costs may actually lower the persistence of the real exchange rate, a finding that is in contrast to much of the emphasis of the empirical literature.
\end{abstract}

JEL Classifications: E32, F31, F41.

Keywords: International business cycles, terms of trade, real exchange rates, transport costs 


\section{Introduction}

This paper considers whether frictions in the international trade of goods might be important for understanding movements in international relative prices over the business cycle. In particular, we analyze how costs of transportation between countries affect the volatility and persistence of the terms of trade and the real exchange rate as well as comovements of the terms of trade with other key variables. Understanding the high volatility and persistence of these two relative prices is an important issue in international business cycle theory and international finance. It is well documented that, at least in the short-run, the law of one price ( the $L O P$ hereafter) and purchasing power parity ( $P$ PP hereafter) seem to be violated (see e.g. Goldberg and Knetter, 1996, and Rogoff, 1997, for recent surveys of the literature). A standard reference for explaining such deviations from the $L O P$ and $P P P$ is transport costs, for example Krugman and Obstfeld (1991) list transport costs as one of three potential explanations for the negative empirical evidence on absolute $P P P^{1}$. Furthermore, there is some empirical evidence that transport costs explain some of the variations in prices across geographical areas, see e.g. Engel and Rogers (1996).

We introduce transport costs into an international business cycle model and analyze the quantitative importance of this friction. We do not expect transport costs to be the only explanation for the observed volatilities in relative prices, but we simply investigate their potential in contributing towards the large and persistent fluctuations than can be observed in relative prices. The analysis is a natural continuation of other lines of research in international economics where such costs have a prominent role. For example, in international trade theory, transport costs are important in explaining both the spatial pattern of trade and the existence non-traded goods (see for example Obstfeld and Rogoff, 1996, chapter 4), and in the literature on economic geography, transport costs contribute to the explanation of the spatial location of production activities (see e.g. Krugman and Venables, 1995, or Venables, 1996). We focus the attention on the role of transports costs in accounting for the "price puzzle" and in explaining the high volatility and persistence of real exchange rates. The "price puzzle" is the fact highlighted by Backus, Kehoe and Kydland $(1994,1995)$ that international business cycle models can account only for a fraction of the observed variability in the terms of trade.

The paper studies a two-country two-good international business cycle model in which it is costly to transfer commodities between countries. We deviate from the standard assumption of "iceberg costs" (according to which a fraction of exports melts during transports) and model instead the transport sector as any other sector of the economy that produces output with an input of factors of production and intermediate goods. This is motivated by the observation that transport sectors account for non-trivial shares of factor inputs in the OECD.

Transport costs affect terms of trade movements through two channels. First, transport costs make imports more costly. Secondly, since imports are produced by the transport sector, the direct link between the terms of trade and the marginal rate of substitution between foreign and domestic goods is broken. The real exchange rate is non-constant in the model for two reasons.

\footnotetext{
${ }^{1}$ Absolute PPP refers to the equality between the level of the exchange rate and the ratio of the levels of domestic and foreign price indices. Relative PPP refers to the equality of the rate of depreciation of the currency and the inflation differential. Absolute PPP implies relative PPP but the opposite is not true.
} 
First, consumption baskets differ across countries. Secondly, the existence of transport costs implies that the $L O P$ is violated.

Our findings can be summarized as follows. First, transport costs increase terms of trade variability but the quantitative effect is small. In the baseline parameterization of our model, the introduction of transport costs increases the standard deviation of the terms of trade by $10-20 \%$. Compared to the data the improvement in the performance of the model is modest: the model implies a standard deviation that is 4-5 times lower than in the OECD postwar data. We find a similar result as far as the ability to account for the volatility of the real exchange is concerned. Transport costs increase the standard deviation of the real exchange rate by around 20 percent but the implied standard deviation is still at least 8 times lower than in the data. One surprising result is that the international business cycle model with frictionless trade implies a persistence of the real exchange rate that is in the upper end of the empirical estimates and that transport costs actually lowers the persistence of this relative price. Finally, we show that mis-measurement of the price level due to using fixed weight indexes may account for as large an increase in measured real exchange rate variability as the introduction of transport costs.

There is one potential way in which the existence of transport costs might lead to substantially larger effects on the terms of trade volatility and real exchange rate volatility. When we specify the transport sector production technology by a function that is almost equivalent to a Leontief production function we find that the standard deviation of the terms of trade increases to 1.6 percent and the standard deviation of the real exchange rate increases to 1.4 percent. These numbers are relatively close to the empirical estimates. The increased volatility of the relative prices is due to much larger implied volatility of transport costs. This case, however, suffers from much too high variability of transport sector value added.

The remainder of this paper is organized as follows. In Section 2 we briefly review the empirical regularities of terms of trade and real exchange rate movements. The model and its calibration is presented in Section 3. Section 4 examines the implications for the behavior of the terms of trade. Section 5 looks into the implied real exchange rate dynamics. Finally, we summarize and conclude in Section 6.

\section{Empirical Regularities}

In this section we briefly review the main empirical regularities that we want to address. Table 1 reports some summary statistics of the terms of trade and real exchange rate movements for 9 major OECD countries. The table is based on quarterly data for the period 1970-1992 taken from the OECD national accounts. All data except nominal exchange rates were seasonally adjusted from the source. The data were detrended using the Hodrick-Prescott filter.

The first part of the table summarizes the variability of the terms of trade (measured by the implicit import price deflator divided by the implicit export price deflator), output (measured by real $G D P$ ) and net-exports defined as nominal exports less nominal imports as a fraction of nominal GDP. As Backus, Kehoe and Kydland $(1994,1995)$ we find that the standard deviation of the terms of trade exceeds the standard deviation of output in all countries. Typically the standard 
deviation of the terms of trade is around 3 percent per quarter but this number varies somewhat across countries. The main outliers are Australia and Japan where the standard deviations exceed 6 percent. As a fraction of the standard deviation of output there is even greater variation but a number of countries cluster around 1.7-1.8. The standard deviation of net-exports is typically around 1 percent with the US being the main outlier. Fluctuations in the terms of trade are persistent in all countries with first-order autocorrelations between 0.75 and 0.89 .

Net-exports and the terms of trade are typically negatively correlated contemporaneously. We find a negative correlation for seven out of the nine countries (Canada and the US are the two exceptions to the rule) and in France, Italy, Japan, Switzerland, and the UK this correlation is substantial and around -0.50 to -0.60 . There is less cross-country consistency in the relationship between the terms of trade and output. In Canada and Switzerland output and the terms trade are positively correlated with correlation coefficients around 0.40 while in the remaining countries the correlations are either small or negative. The largest negative correlation is observed for Japan $(-0.21)$.

Next we look at the real exchange rate. There is an extensive literature on empirical tests of LOP and PPP, see e.g. Isard (1977), Kravis and Lipsey (1978) or the excellent surveys by Froot and Rogoff (1993) and Rogoff (1997) for evidence on PPP, and Goldberg and Knetter (1996) for an excellent survey on the evidence on LOP. Most of the literature agree that these two principles are violated in the short-run whereas the opinions about long-run deviations are more mixed. For example, Devereux (1997) concludes that the evidence is in favor of long-run $P P P$ while Ceglowski (1994) concludes that the $L O P$ is violated even in the long-run (which is inconsistent with long-run $P P P)^{2}$.

Here we concentrate on the business cycle variations and persistence of the fluctuations in the real exchange rate. The last four rows of Table 2 summarize the variability and persistence of real exchange rate movements. The real exchange rate $p^{1}$ is defined against the US and we compute it from $p^{1}=e^{X / U S \$}\left(P^{U S} / P^{X}\right)$ where $e^{X / U S \$}$ is the nominal exchange rate of the currency of country $X$ against the US dollar and $P^{Z}$ is the implicit consumption deflator of country $Z$. The real exchange rate $p^{2}$ is defined equivalently but using Germany as the reference country.

We find large variations in real exchange rates for all countries in the sample. When defined against the US the typical standard deviation of the real exchange rate is close to $8 \%$ per quarter while it seems slightly lower when defined against the German Mark. It seems that the properties depend on the reference country since the standard deviation of $p^{2}$ is lower for all European countries than the standard deviation of $p^{1}$ while the opposite is true for Canada and Australia. This might indicate that the nominal exchange rate regime influences the real exchange rate movements since many of the European countries have either been members of the Exchange Rate Mechanism or have pegged the Deutchmark for a substantial part of the sample period. The effects of exchange rate regimes on real exchange rate movements is well-documented in the literature, see for example Gensberg (1978), Frenkel (1981) or Cumby and Obstfeld (1984).

Another aspect of these movements is that real exchange rate movements tend to be very

\footnotetext{
${ }^{2}$ There are also proponents of $P P P$ as a very succeful theory of exhange rate determination even at higher frequency variations, see e.g. McCloskey and Zecher (1984) for an interpretation of the Classical Gold Standard data.
} 
persistent $^{3}$. When defined against the US dollar we find a typical first-order autocorrelation between 0.70 and 0.80. This number is lower for the European countries when Germany is used as the reference country but with the exception of Italy it is still above 0.6 for all countries.

Thus, in summary, in the data there is substantial variability in the terms of trade. Terms of trade movements are persistent and terms of trade are negatively related with net-exports for most countries. Real exchange rates are very volatile and they show considerable persistence.

\section{The Model Economy}

In this section we formulate an international business cycle model with transport costs. In order to make the results comparable to those obtained earlier in the literature, we keep the basic model as close as possible the Backus, Kehoe and Kydland (1994) two-country two-good international business cycle model.

The world consists of two countries indexed by the subscript $j=1,2$. Each country is inhabited by a large number of identical, infinitely lived households who maximize expected present discounted utility. All agents behave competitively and asset markets are complete. Agents in each country are represented by a single representative stand-in agent. In addition to households there is also a government in each country. Governments are assumed to purchase goods and finance spending by lump-sum taxation. The two countries are specialized in the production of a single output good that can be traded internationally. Final goods, which are not traded, are produced by combining the domestic good with the imported good.

Households in country $j \in\{1,2\}$ maximize discounted expected lifetime utility given by:

$$
U_{j s}=E_{s} \sum_{t=s}^{\infty} \beta^{t-s}\left\{\left[c_{j t}^{\theta} L_{j t}^{1-\theta}\right]^{1-\sigma}-1\right\}
$$

where $E_{s}$ is the mathematical expectations operator conditional on information available at date $s \leq t ; c_{j t}$ is the consumption of goods of the representative household in country $j$ at date $t$ and $L_{j t}$ is the consumption of leisure; $\theta \in[0 ; 1]$ is a share parameter, and $\sigma>0$ is the inverse of the intertemporal elasticity of substitution.

Production of output goods is described by a constant returns to scale Cobb-Douglas technology:

$$
y_{j t}=z_{j t}\left(k_{j t}^{y}\right)^{1-\alpha}\left(n_{j t}^{y}\right)^{\alpha}
$$

where $y_{j t}$ is the amount of output produced in country $j$ at date $t ; z_{j t}$ is a stochastic technology shock; $k_{j t}^{y}$ (respectively $n_{j t}^{y}$ ) is the input of capital (respectively labor) in the output sector. $\alpha \in$ $(0,1)$ is the labor share in the production of output goods.

Output goods can be used as an input to domestic production of final goods or they can be exported. The resource constraints are given by:

\footnotetext{
${ }^{3}$ Since the moments refer to Hodrick-Prescott filtered data they are uninformative about the existence of unit roots in the real exchange rates. The Hodrick-Prescott filter will render stationary any series that is integrated up to order 4 .
} 


$$
y_{j t}=d_{j t}+x_{j t}
$$

where $d_{j t}$ is the domestic use of domestic goods and $x_{j t}$ is domestic exports.

The production of final goods is specified by a homogeneous CES production function known as the Armington (1969) aggregator :

$$
V_{j t}=\left[\omega_{1} d_{j t}^{1-\rho}+\omega_{2} m_{j t}^{1-\rho}\right]^{1 /(1-\rho)}
$$

where $V_{j t}$ is the output of final goods, and $m_{j t}$ denotes the input of imported goods. $\omega_{1}$ and $\omega_{2}$ are share parameters (indicating "taste for homegoods"), and $1 / \rho$ is the elasticity of substitution between domestic goods and imports.

The resource constraint for the final goods is given by:

$$
V_{j t}=c_{j t}+g_{j t}+i_{j t}^{y}+i_{j t}^{c y}+i_{j t}^{t r}+i_{j t}^{c t r}
$$

where $g_{j t}$ is government spending in country $j$ at date $t, i_{j t}^{y}$ is investment in capital used in the output sector, $i_{j t}^{c y}$ is the capital adjustment cost associated with accumulation of capital used in the output sector, and $i_{j t}^{t r}$ and $i_{j t}^{c t r}$ are the investment variables for the transport sector. Capital adjustment costs are introduced here in order to limit capital flows between the two sectors within each country ${ }^{4}$.

It is standard to assume that trade in goods is frictionless, see e.g. Backus, Kehoe and Kydland (1994, 1995), Arvinitis and Mikkola (1996), and Ravn (1997). We deviate from this and introduce transport costs in international trade. Backus, Kehoe and Kydland (1992) introduced iceberg transport costs (transport costs related only to the amount of goods traded between countries) in order to investigate the importance of such costs for the international transmission of business cycles $^{5}$. Crucini (1997), who also looks at the international transmission mechanism, assumes instead that the transport sector requires a fixed input of labor per unit of imports (i.e. the transport sector is specified by a Leontief technology). We allow for a more general transport technology and assume that imports into a country are produced by combining exports from other countries with domestic factor inputs. We also assume that the transport technology has constant returns to scale to all inputs jointly.

The transport sector is specified by a CES production function in foreign exports and a CobbDouglas composite of domestic inputs of labor and capital:

$$
m_{j t}=\left[\pi_{1} x_{i t}^{1-\mu}+\pi_{2}\left\{\left(k_{j t}^{t r}\right)^{1-\gamma}\left(n_{j t}^{t r}\right)^{\gamma}\right\}^{1-\mu}\right]^{1 /(1-\mu)}, i \neq j
$$

where $x_{i t}$ denotes foreign exports. $k_{j t}^{t r}$ and $n_{j t}^{t r}$ are the inputs of capital and labor in the transport sector in country $j$ at date $t . \pi_{1}, \pi_{2} \geq 0$ are share parameters in the transport technology, $\gamma \in[0,1]$

\footnotetext{
${ }^{4}$ It is common to introduce capital adjustment costs into two-country single-goods models in order to limit investment variability and in order to ensure the existence of a saddle-path solution. We include these costs in order to address the same problem of capital mobility between the two sectors within the same country.

${ }^{5}$ They specified the iceberg costs to be quadratic in the amount of good traded internationally.
} 
is the labor share in the Cobb-Douglas composite, and $1 / \mu \geq 0$ is the elasticity of substitution between foreign exports and the Cobb-Douglas composite.

This specification encompasses as special cases, the standard model with no transport costs for $\pi_{1}=1$ and $\pi_{2}=0$, and the iceberg model with linear transport costs for $\pi_{1}<1$ and $\pi_{2}=0$. For $1 / \mu \rightarrow \infty$ the specification implies that imports can be produced without inputs of foreign exports, a case that is clearly unrealistic. In the other extreme case, $1 / \mu \rightarrow 0$, the production function does not allow for substitution between foreign exports and domestic factor inputs but as long as $\gamma \neq\{0,1\}$ the import sector can still substitute between labor and capital.

Capital accumulation is given by:

$$
\begin{aligned}
& k_{j t+1}^{y}=\left(1-\delta_{y}\right) k_{j t}^{y}+i_{j t}^{y} \\
& k_{j t+1}^{t r}=\left(1-\delta_{t r}\right) k_{j t}^{t r}+i_{j t}^{t r}
\end{aligned}
$$

where $\delta_{y}, \delta_{t r} \in[0,1]$ denote the rates of depreciation of the two capital stocks. Capital adjustment costs are specified by:

$$
\begin{gathered}
i_{j t}^{c y}=\phi^{y}\left(i_{j t}^{y}, k_{j t}^{y}\right), \frac{\partial \phi^{y}}{\partial i_{j t}^{y}} \geq 0, \frac{\partial \phi^{y}}{\partial k_{j t}^{y}} \leq 0 \\
i_{j t}^{c t r}=\phi^{t r}\left(i_{j t}^{t r}, k_{j t}^{t r}\right), \frac{\partial \phi^{t r}}{\partial i_{j t}^{t r}} \geq 0, \frac{\partial \phi^{t r}}{\partial k_{j t}^{t r}} \leq 0
\end{gathered}
$$

The use of time is constrained by:

$$
L_{j t}+n_{j t}^{y}+n_{j t}^{t r} \leq T
$$

where $T$ is the endowment of time. Finally, it is assumed that government expenditures are financed by lump-sum taxation.

Equilibrium relative prices in this economy can be derived as follows. First we find transport costs. Transport costs can be measured by the price of the imports produced by the transport sector relative to the price of goods purchased abroad (foreign exports), and we denote this ratio by $p_{j t}^{m} / p_{i t}^{x}$. This relative price can be derived from the cost function of the transport sector. Using the fact that due to competition there is marginal cost pricing, we get that ${ }^{6}$ :

$$
\widehat{p}_{j t}=\frac{p_{j t}^{m}}{p_{i t}^{x}}=\pi_{1}^{1 /(\mu-1)}\left[1+\frac{\pi_{2}}{\pi_{1}}\left(\frac{n_{j t}^{t r}}{x_{i t}}\right)^{\gamma(1-\mu)}\left(\frac{k_{j t}^{t r}}{x_{i t}}\right)^{(1-\gamma)(1-\mu)}\right]^{-\mu /(1-\mu)}
$$

${ }^{6}$ The cost function in the transport sector is given by:

$$
C_{j}^{m}\left(m_{j}, p_{i}^{x}, w_{j}, r_{j}\right)=\left[\pi_{1}^{1 / \mu}\left(p_{i}^{x}\right)^{(\mu-1) / \mu}+\pi_{2}^{1 / \mu} \varkappa\left(w^{\gamma} r^{(1-\gamma)}\right)^{(\mu-1) / \mu}\right]^{\mu /(\mu-1)} m_{j}
$$

where $\varkappa=\left(\frac{(1-\gamma)^{\gamma-1}}{\gamma^{\gamma}}\right)^{(\mu-1) / \mu}$ and $\left(p_{i}^{x}, w_{j}, r_{j}\right)$ are the factor prices at which the import sector hires foreign exports, and domestic labor and capital. 
This relationship gives us the price of domestic imports relative to foreign exports. Notice that transport costs are non-constant as long as $\pi_{2} / \pi_{1} \neq 0$ and that $\widehat{p}=1$ for $\pi_{1}=1$ and $\pi_{2}=0$ (i.e. the case of no transport costs).

Next, the relative price of domestic imports to domestic exports can be computed from the marginal rate of transformation between $d_{j t}$ and $m_{j t}$ in the Armington aggregator, since domestically used domestic goods must sell at the same price as domestic exports. Thus,

$$
\widetilde{p}_{j t}=\frac{p_{j t}^{m}}{p_{j t}^{x}}=\frac{\omega_{2}}{\omega_{1}}\left(\frac{d_{j t}}{m_{j t}}\right)^{\rho}
$$

We can now derive the terms of trade. The relative price of the good purchased abroad to the domestic export good follows from combining the two preceding expressions ${ }^{7}$ :

$$
p_{j t}=\frac{p_{i t}^{x}}{p_{j t}^{x}}=\frac{p_{i t}^{x}}{p_{j t}^{m}} \frac{p_{j t}^{m}}{p_{j t}^{x}}=\frac{\widetilde{p}_{j t}}{\widehat{p}_{j t}}
$$

This makes it clear that transport costs affect the terms of trade through two basic channels. First, transport costs enter directly into the determination of the terms of trade through variations in $\widehat{p}$. But, on top of this, transport costs also affect the equilibrium quantities of $d_{j t}$ and $m_{j t}$ and thus $\widetilde{p}_{j t}$. It is also important to notice that the direct link between the marginal rate of substitution between domestic and foreign goods, which would determine the terms of trade in the absence of frictions, and the terms of trade is broken in this model due to the existence of the transport sector. In particular, when there are no transport costs we have that $p_{j t}$ is given by $\left(\omega_{2} / \omega_{1}\right)\left(d_{j t} / x_{j t}\right)^{\rho}$ i.e. by the marginal rate of transformation between domestic and foreign goods, but due to transport costs this relationship no longer holds in the present model. This latter observation will turn out to be important.

Aggregate output is measured by the sum of the value added in the transport sector and the value added in the output sector at fixed base year relative prices. Using the output goods as the numeraire, we define aggregate output in "fixed prices", $y^{A}$, by:

$$
y_{j t}^{A}=y_{j t}+\frac{p_{j}^{m}}{p_{j}^{x}} y_{j t}^{t r}
$$

where the absence of time-indices indicates that the relative price is evaluated at the steady-state. Similarly, aggregate output in "current prices", $Y^{A}$, is given by:

$$
Y_{j t}^{A}=y_{j t}+\frac{p_{j t}^{m}}{p_{j t}^{x}} y_{j t}^{t r}
$$

Value added in the transport sector is given by:

$$
y_{j t}^{t r}=\left[\left(n_{j t}^{t r}\right)^{\gamma}\left(k_{j t}^{t r}\right)^{1-\gamma}\right]^{\mu} m_{j t}^{1-\mu}
$$

Finally, net-exports are defined by domestic exports less goods purchased abroad as a percentage of domestic output, all measured in terms of the current price of the domestic good:

\footnotetext{
${ }^{7}$ The terms of trade can also be computed from the marginal rate of substitution directly as $p_{t}=$ $\left[\left(\partial V_{1 t} / \partial m_{1 t}\right) /\left(\partial V_{1 t} / \partial d_{1 t}\right)\right]\left[\partial m_{1 t} / \partial x_{j t}\right]$ which is equal to $\pi_{1} \frac{\omega_{2}}{\omega_{1}}\left(\frac{d_{j t}}{m_{j t}}\right)^{\rho}\left(\frac{m_{j t}}{x_{j t}}\right)^{\mu}$. This expression is identical to the relationship in (14) along the equilibrium path.
} 


$$
n x_{j t}=\frac{x_{j t}-p_{j t} x_{i t}}{Y_{j t}^{A}}
$$

This completes the description of the model economy. We now move on to quantifying the model. This requires calibrating the model parameters.

\subsection{Calibration}

The model is calibrating using standard parameter values whenever possible. The details of the derivation of the steady-state conditions are given in the appendix. We make a number of simplifying assumptions. First, we assume that the two economies have identical steady states. Secondly, we make four normalizations: (a) there are no capital adjustment costs along the steady state path; (b) the steady state level of production of output goods, $y$, is equal to the steady state production of final goods, $V$; (c) steady state imports, $m$, equal steady-state exports, $x$; (d) we normalize the time endowment, $T$, to one.

The discount factor, $\beta$, is chosen such that it is consistent with a $4 \%$ annual real interest rate. We use the standard value of 2 for $\sigma$, the inverse of the intertemporal elasticity of substitution. Agents are assumed to use $30 \%$ of their time endowment on market activities and we set the government spending share equal to $20 \%$. Next, we assume that the steady-state share of imports is equal to $20 \%$, a value close to the OECD average import share. We set the labor share in the output sector, $\alpha$, equal to the standard estimate of $64 \%$ used by Backus, Kehoe and Kydland and we set the two depreciation rates equal to the standard value of $2.5 \%$ per quarter. The elasticity of substitution between domestic and foreign goods in the Armington aggregator (4), is set equal to 1.5 as in Backus, Kehoe and Kydland (1994).

Given the import share, we calibrate $\pi_{1}$ (the share parameter in the transport sector production function) such that it is consistent with the following relationship:

$$
\pi_{1}=\frac{\gamma M_{s}}{\gamma M_{s}+\alpha\left(n^{t r} / n^{y}\right)}
$$

where $M_{s}$ is the steady-state import share. This relationship depends on the ratio of hours worked in the two sectors. Table 1 lists some summary statistics for transport sector variables based on data from the OECD Intersectorial Database (ISDB). Transport sector employment accounts on average for $6.8 \%$ of total employment (i.e. $n^{t r} / n^{y}=7.3 \%$ ). This calculation, however, overestimates the transport sector employment in terms of our model since the ISDB classification includes not only international transports but also national transports and communication and storage. We use the value of $7.3 \%$ for $n^{t r} / n^{y}$ but keep in mind that this is an upper estimate. We will also show in Section 4.2 that the results are not too sensitive to the exact value used.

The steady state ratio of capital employed in the output sector to steady state output and the division of capital between sectors are determined by the following relationships:

$$
\frac{k^{y}}{y}=\frac{\beta \alpha\left(1-M_{s}\right)^{-\rho} \omega_{1}}{1-\beta(1-\delta)}
$$




$$
\frac{k^{t r}}{k^{y}}=M_{s}\left(\frac{1-M_{s}}{M_{s}}\right)^{\rho} \frac{1-\gamma}{1-\alpha} \frac{\omega_{2}}{\omega_{1}}\left(1-\pi_{1}\right)
$$

From Table 1 one notices that the transport sector is noticeably more capital intensive than the rest of the economy in most of the countries; on the average, the capital output ratio is $30 \%$ higher in the transport sector than for the economy as a whole. As a percentage of the total capital stock, the transport sector accounts for $9.6 \%\left(k^{t r} / k^{y}=10.6 \%\right)$. However, Norway is an outlier and when excluding this country the transport sector employs approximately $9 \%$ of the capital stock $\left(k^{t r} / k^{y}=9.9 \%\right)$. We choose $\gamma$ (the labor share in transports) such as to imply that $k^{t r} / k^{y}=0.099$. Given this we get $\pi_{1}, \omega_{1}, \omega_{2}$, and $k^{y} / y$. The calibration implies that $\left(\gamma, \pi_{1}, \omega_{1}, \omega_{2}, k^{y} / y\right)=$ $(0.57,0.709,0.796,0.446,9.507)$. It then follows that $\left(s_{i^{y}}, s_{i^{t r}}\right)=(23.8 \%, 2.3 \%)$.

In the import production function we need to calibrate the share parameter $\pi_{2}$ and the elasticity of substitution, $1 / \mu$. A high elasticity of substitution implies that imports can be produced with little input of exports. To avoid this, we assume a small elasticity of substitution and let $1 / \mu=0.1$. However, since this is a parameter of which we know relatively little, we perform some robustness checks. $\pi_{2}$ is calibrated such that imports equal exports along the steady state path.

The capital adjustment cost functions are calibrated such that there are no adjustment costs along the steady state path. We use the following quadratic specifications:

$$
\phi^{s}\left(i_{j t}^{s}, k_{j t}^{s}\right)=\eta\left(\frac{i_{j t}^{s}-\delta k^{s}}{k^{s}}\right)^{2}, s=y, t r
$$

and choose $\eta$ so that we reproduce the relative variability of total investments to output observed in the data.

Finally, we need to calibrate the stochastic processes for $z_{1 t}, z_{2 t}, g_{1 t}$ and $g_{2 t}$. We assume that $\left(\ln z_{1 t}, \ln z_{2 t}\right)^{\prime}$ is generated by a stationary vector stochastic process:

$$
\left(\begin{array}{l}
\ln z_{1 t} \\
\ln z_{2 t}
\end{array}\right)=\left(\begin{array}{l}
a_{1} \\
a_{2}
\end{array}\right)+\left(\begin{array}{ll}
\kappa_{1} & \kappa_{2} \\
\kappa_{3} & \kappa_{4}
\end{array}\right)\left(\begin{array}{l}
\ln z_{1 t-1} \\
\ln z_{2 t-1}
\end{array}\right)+\left(\begin{array}{l}
\epsilon_{1 t} \\
\epsilon_{2 t}
\end{array}\right)
$$

where $\left(\begin{array}{ll}\epsilon_{1 t} & \epsilon_{2 t}\end{array}\right)^{\prime} \sim$ n.i.d. $\left(0, \sum_{\epsilon}\right)$ and $a_{1}$ and $a_{2}$ are chosen such that we reproduce the assumed steady state values of $z_{1}$ and $z_{2}{ }^{8}$. We use the estimation results in Backus, Kehoe and Kydland $(1992)^{9}$ and assume that $\kappa_{1}=\kappa_{4}=0.906$ and $\kappa_{2}=\kappa_{3}=0.088, \sigma_{\epsilon_{1}}^{2}=\sigma_{\epsilon_{2}}^{2}=\sigma_{\epsilon}^{2}=0.00852^{2}$, $E\left(\epsilon_{1} \epsilon_{2}\right)=0.256 \sigma_{\epsilon}^{2}$.

Government spending shocks are assumed to be independent across countries and to be generated by first-order autoregressive processes:

$$
\ln g_{j t}=\left(1-\kappa_{g}\right) \ln g_{j}+\kappa_{g} \ln g_{j t-1}+\vartheta_{t}
$$

where $\kappa_{g} \in[0,1)$ and $\vartheta_{t} \sim i . i . d .\left(0, \sigma_{\vartheta}^{2}\right)$. We assume that $\kappa_{g}=0.95$ and $\sigma_{\vartheta}=0.02$.

\footnotetext{
${ }^{8}$ The vector $a=\left(\begin{array}{ll}a_{1} & a_{2}\end{array}\right)^{\prime}$ is given by $\left(I-K_{z}\right)^{-1} \ln z$ where $K_{z}$ is the matrix of autoregressive terms and $\ln z=\left(\begin{array}{ll}\ln z_{1} & \ln z_{2}\end{array}\right)^{\prime}$.

${ }^{9}$ We also experimented with a specification based on the results in Ravn (1997), $\kappa_{1}=\kappa_{4}=0.90$ and $\kappa_{2}=\kappa_{3}=$ $0.05, \sigma_{\epsilon}^{2}=0.00852^{2}, E\left(\epsilon_{1} \epsilon_{2}\right)=0.256 \sigma_{\epsilon}^{2}$. This alternative specification, however, hardly change the results.
} 
We these parameter values in hand we are ready to proceed to the quantitative evaluation of the model.

\section{Implications for Terms of Trade Movements}

We now turn to the quantitative implications of the model and we first concentrate on the behavior of the terms of trade. We report the average results over 100 simulations for a time horizon of 100 quarters (using an extra 50 observations as initial conditions). As the OECD data, we filtered the simulated data with the Hodrick-Prescott filter.

\subsection{A Model with no Capital in the Transport Sector}

It is useful to start the analysis by looking at a special case of the model in which $\gamma=1$ so that the transport sector does not employ any capital. This case is instructive as it gives some intuition for the results from the more general model. The restriction implies that the import production function is specified as:

$$
m_{j t}=\left[\pi_{1} x_{i t}^{1-\mu}+\pi_{2}\left(n_{j t}^{t r}\right)^{1-\mu}\right]^{1 /(1-\mu)}
$$

Under this specification there is less flexibility in the transport sector since it only relies on labor and foreign exports.

\subsubsection{The Baseline Specification}

Before presenting the quantitative results we investigate the impact of shocks to the economy on output, trade, and relative prices. Figure 1 presents impulse response functions after a one percent increase in domestic technology (in Panel A) and a one percent increase in domestic government spending (in Panel B). We also illustrate transport costs measured by $\widehat{p}_{1 t}$. All variables except net-exports are illustrated in percentage deviations from the steady-state.

An increase in domestic productivity increases output and the relative price of foreign goods. On impact, output increases by 1.2 percent above its steady-state level and then gradually returns to its steady-state. The terms of trade increase as well, but with a smaller elasticity than output. On impact the percentage increase in the terms of trade is slightly below 0.4 percent but the increase continues until around 1.5 years after the initial shock occurred. At this point the terms of trade peak at 0.42 percent above its steady-state value. This increase in the terms of trade is slightly higher than in models without transport costs. Had there been no transport costs, terms of trade would increase by 0.3 percent on impact and reach a peak at 0.35 percent. Thus, it seems that the effect of adding transport costs might be relatively small and in response to technology shocks, terms of trade would counterfactually have a smaller variability than output.

As discussed above, the increase in terms of trade variability that is observed relative to the model without transport costs is caused either by a decrease in trade variability (because trade is costly) or by variations in transport costs (which break the direct link between traded quantities and relative prices). Under the baseline parameterization, transport costs vary relatively 
modestly. On impact transport costs increase by less than 0.1 percent and they remain low over the adjustment process. Thus, the increased terms of trade variability is related to a decrease in trade variability. This can be seen from noting that net-exports decrease on impact by around 0.2 percent in our economy which has to be compared with 0.3 percent in an economy without transport costs.

Panel B looks at the effects of changes in government spending. The first observation we make is that this type of (more demand related) shocks to the economy causes bigger adjustment of prices than in quantities. A 1 percent increase in government spending increases output by 0.06 percent and decreases the terms of trade by 0.085 percent. The relative magnitude of these responses suggests that such shocks might be important but the small absolute magnitudes of the responses suggests that technology shocks are likely to dominate.

These insights are confirmed by the stochastic simulations of the model. In Table 4 we report the results for several different parameterizations. In the first two rows we compare the moments of the model without transport costs with those for the baseline parameterization. We find that introducing transport costs increases the standard deviation of the terms of trade from 0.59 percent per quarter to 0.65 percent per quarter. The standard deviation of the terms of trade relative to the standard deviation of output increases from 0.46 to 0.52 by adding transport costs. Thus, under the baseline parameterization, transport costs cannot account for the quantitative difference between theory and data. Furthermore, as anticipated, the increase in the terms of trade variability comes at the cost of lower net-export variability.

It is worthwhile to notice that the model implies an autocorrelation of the terms of trade that is close to the average of the data in Table 1. In the data the average first-order autocorrelation of the terms of trade is 0.81 and the model implies a first-order autocorrelation of 0.78 . However, this success is not related to the existence of transport costs, since this number is approximately the same in the frictionless economy.

It is also worth noticing that the model, regardless of the existence of transport costs, implies a strong positive correlation between terms of trade and output and a moderate negative correlation between net-exports and the terms of trade. This is explained by the dominance of productivity shocks and their effects on the dynamics of the model: Productivity shocks lead to positive comovements of the terms of trade and output since they increase output and the relative price of foreign goods. At the same time, in the short run, any such shock leads to a worsening of the trade balance. These implications contrast somewhat with the data. In the data, there is a relatively strong negative correlation between terms of trade movements and output in most countries while there is some cross-country variation in the correlation between the terms of trade and net-exports with a number of countries having moderate negative correlations and some having larger positive correlations.

In summary, the model with transport costs cannot account for the difference between theory and data in terms of neither the variability in the relative price of exports and imports, nor the relationship between terms of trade movements and output and net-exports.

Before proceeding with the sensitivity analysis, we check whether the inclusion of government spending is relevant, and, in the third row, we assume that it is constant. As the discussion above indicated this has little effect on real variability but lowers the terms of trade variability 
even further. When the standard deviation of government spending shocks is set equal to 0 , the standard deviation of the terms of trade decreases from 0.65 percent to 0.57 percent while the standard deviation of output decreases from 1.26 percent to 1.23 percent. The model with no shocks to government spending also implies counterfactually a more positive relationship between the terms of trade and output. These observations suggest that government spending has very small quantitative effects in the model.

\subsubsection{Sensitivity to the Transport Sector Modeling}

We now investigate whether the results are sensitive to the size of the transport sector and the elasticity of substitution in this sector. Rows (4) to (7) look at alternative experiments.

In Row 4 we halve the size of the transport sector and assume that it accounts for 3.4 percent of total employment. This change in the parameterization has little effect on the moments of the model and does not seem to be very important for the conclusions. This is confirmed in Row 5 where we instead increase the share of employment in the transport sector to 10.4 percent of total employment. Again no moments are significantly affected. Thus the precise value of this parameter matters very little.

Row 6 reports the moments of the model when the elasticity of substitution in the transport sector is lowered from 0.1 to 0.01 . This has a large effect on the moments of the terms of trade. Our results imply that the standard deviation of the terms of trade increases to 1.57, almost two and half times as much as in the baseline model. At the same time, this change in the calibration also brings the correlations of the terms of trade with output and net-exports much closer to what can be observed in the data. The reason for this is that we get much larger variations in transport costs since there is little scope for substitution between foreign exports and domestic input of labor in this sector. An increase in import demand is associated with an increase in import sector employment and this increases the transport costs which then leads to larger variations in the terms of trade.

In Figure 2 we illustrate some key moments as a function of the elasticity of substitution in the transport sector, $1 / \mu$. In the first panel we show the standard deviation of output, netexports, the terms of trade and the import ratio defined by $m_{j t} / d_{j t}$. The figure illustrates that as long as the elasticity of substitution does not become extremely small, the precise value of this parameter matters very little for the moments of interest. However, for $1 / \mu \approx 0$, the variances of net-exports and terms of trade increase sharply. However, output and import ratio variabilities are almost unaffected. Furthermore, it seems that for a small enough elasticity of substitution, one can reproduce the big variability of the terms of trade relative to output. Thus, it appears that transport costs can resolve the "price puzzle".

This resolution, however, does not survive closer scrutiny. The reason is that the value added in the transport sector becomes counterfactually volatile for $1 / \mu \rightarrow 0$. In Figure 2 (second panel) we illustrate the standard deviation of transport sector value added, aggregate output and transport costs. When the elasticity of substitution approaches 0 , the variability of value added in the transport sector rises sharply as does the volatility of transport costs.

The enormous relative volatility of the transport sector is counterfactual. Table 2 lists the 
standard deviations of Hodrick-Prescott filtered annual data for aggregate output and transport sector output ${ }^{10}$. In these data the output of the transport sector is more variable than aggregate output for all countries. On the average, the ratio of the standard deviation of the transport sector output to the standard deviation of total output is 1.85 .

For $1 / \mu=0.01$ the model implies that the standard deviation of value added in the transport sector is around 4.5 times higher than aggregate output, an estimate that is counterfactually high. Based on this we also carry out an experiment in which we choose the elasticity of substitution, $1 / \mu$, such that we match the relative variability of output of the two sectors which implies that $1 / \mu \approx 0.021$. The results for this parameterization are reported in Row (7) of Table 4. We find a standard deviation of the terms of trade of 0.79 percent, an estimate that is well below any number quoted in Table 1. Thus, the model with plausible parameter values cannot reproduce the high volatility of the terms of trade observed in the data.

In summary, adding transport costs to the two-country two-good international business cycle model implies higher terms of trade variability but it does not resolve the "price puzzle". A plausible parameterization of the model implies a standard deviation of the terms of trade of $0.79 \%$ per quarter as compared to $0.59 \%$ in the absence of transport costs and $3 \%$ in the data.

\subsubsection{Other Sensitivity Analyses}

In the last three rows of Table 4 we summarize the results for two final sensitivity analyses. In Row 7 we look at the effects of increasing the steady-state import share to 30\%. As Backus, Kehoe and Kydland (1995) we find that this change in the parameterization has only minor effects. The next row reports the moments when the elasticity between domestic goods and imported goods in the Armington aggregator is lowered to 0.5. This change in the calibration increases the terms of trade variability quite significantly, but as pointed out by Backus, Kehoe and Kydland (1995), this comes at the cost of a counterfactually low variability of the import ratio.

\subsection{Implications of the General Model}

We now turn to the implications of the general model in which the transport sector utilizes both labor and capital. The results of simulations of this model are reported in Table 5.

The quantitative results are very similar to those discussed above. The main differences can be summarized as follows. First, there is a general tendency for slightly higher terms of trade variability. For example, under the baseline parameterization, we find that the general model implies a standard deviation of the terms of trade of 0.71 percent which is around ten percent higher than in the model with no capital in this sector but still well below any number observed in the data. The increase in relative price volatility, however, comes at the cost of lower variability in net-exports. The reason for this is that the elasticity of imports with respect to labor is lower under this specification than in the special case analyzed above and that adjustment costs limit

\footnotetext{
${ }^{10}$ Based on the arguments in Ravn and Uhlig (1997) we adjusted the smoothing parameter of the filter such that the estimated moments relate to the same frequencies as those one isolates with the usual choice of 1600 at the quarterly frequency, which is the frequency we simulate the model for. For the annual data we use a value of 6.25 for the smoothing parameter.
} 
the variability of the capital stock employed in this sector. These two effects together imply that transport costs rise more in response to shocks than in the case analyzed before. This lowers the trade variability and increases adjustments through prices.

The only case where a major difference between the two models appears is for the very low elasticity of substitution where the general model implies a standard deviation of the terms of trade of 0.80 percent, which is substantially below the number we found in the previous section. The reason for this finding is that although very low values of the elasticity of substitution between foreign exports and the Cobb-Douglas composite lead to more volatile costs, there is still scope for substitution between labor and capital. Thus, much smaller values of the elasticity of substitution are needed in order to lead to a major increase in terms of trade variability for this specification.

Since the difference between the model examined before and the general model is due to the capital share, we carry out some sensitivity analysis with respect to this parameter. The baseline parameterization used in Table 5 assumes that the capital share in this sector is equal to 57 percent but this might well be associated with measurement errors. In Figure 3 we illustrate the key moments of the model as functions of the capital share. The picture reveals that unless the transport sector becomes very capital intensive, the exact value used in the parameterization matters relatively little. The question is whether our estimate of the capital share is likely to be biased upwards or downwards. It is probably safe to ascertain that a capital share in the transport sector of $57 \%$ is negatively biased. Our estimate is based on the ISDB classification of this sector which includes both domestic transports as well as communications and storage. International transports are probably more capital intensive than national transports (due to the larger distances covered in international transports). However, even if we were to revise the estimate of $\gamma$ to $80 \%$, a value that seems very high, this would only increase the volatility of the terms of trade to $0.9 \%$ per quarter and, thus, would not resolve the "price puzzle".

\section{Implications for Real Exchange Rate Movements}

In this Section we want assess the extent to which transport costs might contribute to explain the large variations and the high persistence of real exchange rates that was discussed in Section 2. Clearly, many factors are responsible for the negative evidence on PPP and the $L O P$ and transport costs is only one of these. Thus, we do not expect transport costs to be the sole explanation. For example, phenomena such as pricing to market and exchange rate pass through have been shown to be important empirically in the explanation for deviations from the $L O P$ and we do not introduce such features here (for a recent survey, see Goldberg and Knetter, 1997). However, empirical studies typically also find at least some role for transport costs. Among others, Engel and Rogers (1996) find that distance is important in explaining geographical variations in prices even though "border phenomena" (country of purchase) are also important. Transport costs are also a standard textbook example for explaining deviations from $P P P$. For example, in Krugman and Obstfeld (1991) transport costs are mentioned as one of the three main explanations for the negative empirical evidence on $P P P$.

Thus, we look at how much transport costs can potentially explain of the variations in real 
exchange rates. Previously, Dumas (1992) has analyzed the effects of transport costs on the real exchange rate in a continuous time model with trade in capital only and with a linear technology in capital. He found that such costs might be responsible for the very high persistence of real exchange rates that is observed in empirical data. Michael, Nobay and Peel (1997) carry out a time-series econometric test of this hypothesis.

In our model there are two reasons why the real exchange rate might vary. First, preferences may differ across countries. Thus, since the typical bundles that are purchased abroad and at home differ, PPP can be violated even though the $L O P$ holds. In particular, this will be the case out of the steady-state. Secondly, because of the existence of transport costs, the $L O P$ is violated.

To compute the real exchange rate we need the consumer price indices. At this point we think of the model as one in which all final uses of goods are specified by identical $C E S$ functions. The exact consumer price index can be derived from the expenditure functions. The expenditure functions are given by ${ }^{11}$ :

$$
\begin{aligned}
& e_{1}\left(p_{1 t}^{x}, p_{1 t}^{m}, c_{1 t}\right)=\left[\omega_{1}^{1 / \rho} p_{1 t}^{x}+\omega_{2}^{1 / \rho} p_{1 t}^{m(\rho-1) / \rho}\right]^{\rho /(\rho-1)} c_{1 t} \\
& e_{2}\left(p_{2 t}^{x}, p_{2 t}^{m}, c_{2}\right)=\left[\omega_{1}^{1 / \rho} p_{2 t}^{x}+\omega_{1}^{1 / \rho} p_{2 t}^{m(\rho-1) / \rho}\right]^{\rho /(\rho-1)} c_{2 t}
\end{aligned}
$$

where $e_{i}\left(p_{i t}^{x}, p_{i t}^{m}, c_{i t}\right)$ is the expenditure needed for an agent in country $i$ to obtain $c_{i t}$ units of the consumption composite $c_{i t}=\left[\omega_{1} d_{i t}^{1-\rho}+\omega_{2} m_{i t}^{1-\rho}\right]^{1 /(1-\rho)}$. Using the output good of country 1 as the numeraire the price deflators follow as:

$$
\begin{aligned}
& Q_{1}\left(p_{1 t}^{x}, p_{1 t}^{m}\right) \equiv e_{1}\left(p_{1 t}^{x}, p_{1 t}^{m}, c_{1 t}=1\right)=\left[\omega_{1}^{1 / \rho}+\omega_{2}^{1 / \rho} \widetilde{p}_{1 t}^{(\rho-1) / \rho}\right]^{\rho /(\rho-1)} p_{1 t}^{x} \\
& Q_{2}\left(p_{2 t}^{x}, p_{2 t}^{m}\right) \equiv e_{2}\left(p_{2 t}^{x}, p_{2 t}^{m}, c_{2 t}=1\right)=\left[\omega_{2}^{1 / \rho}+\omega_{1}^{1 / \rho} \widetilde{p}_{2 t}^{(1-\rho) / \rho}\right]^{\rho /(\rho-1)} p_{2 t}^{m}
\end{aligned}
$$

The real exchange rate then given as:

$$
q_{1 t}=\frac{Q_{2}\left(p_{2 t}^{x}, p_{2 t}^{m}\right)}{Q_{1}\left(p_{1 t}^{x}, p_{1 t}^{m}\right)}=\left(\frac{\omega_{2}^{1 / \rho}+\omega_{1}^{1 / \rho} \widetilde{p}_{2 t}^{(1-\rho) / \rho}}{\omega_{1}^{1 / \rho}+\omega_{2}^{1 / \rho} \widetilde{p}_{1 t}^{(\rho-1) / \rho}}\right)^{\rho /(\rho-1)} \widehat{p}_{2 t}
$$

If there are no transport costs, $\widetilde{p}_{1 t}=\widetilde{p}_{2 t}$ and that $\widehat{p}_{2 t}=1$. However, the real exchange rate can still deviate from one unless the steady-state import share is equal to $50 \%$ in which case $\omega_{1}=\omega_{2}$. Hence, the real exchange rate can fluctuate even in the model with no transport costs because of differences across countries in preferences.

When transport costs are added to the model, it will no longer be true that $\widetilde{p}_{1 t}=\widetilde{p}_{2 t}$ nor that $\widehat{p}_{2 t}=1$. Thus, in this case, transport costs drive a wedge between relative prices of identical goods across countries and this gives one additional source of real exchange rate variations ${ }^{12}$.

\footnotetext{
${ }^{11}$ We have here used that the domestic good must sell at the same price as the domestic export good in each of the two countries.

${ }^{12}$ However, it is still true that the steady-state value of the real exchange rate is equal to 1.
} 
The question is how important these sources are for real exchange rate variability. In Figure 4 we show the impact on the real exchange rate of a one percent increase in technology (in the top panel) and a one percent increase in government spending (in the lower panel). We also show the real exchange rate implied by the model for $\pi_{1}=1$ and $\pi_{2}=0$ (frictionless trade). In order to decompose the effect on the real exchange rate, we separate the real exchange rate into the part directly accounted for by transport costs (the part associated with $\widehat{p}_{2 t}$ ) and the part due to preference weighted relative price differences $\left(q_{1 t} / \widehat{p}_{2 t}\right)$.

A domestic technology shock lowers the relative price of the domestically produced good. Had there been no transport costs, this would give rise to the real exchange rate dynamics indicated by the function that is denoted by $q^{\text {no transp.cost }}$ (the deviation of national price levels due to differences in preferences). The increased productivity in country 1 increases the relative price of the country 2 good in both countries. Since we have denominated the price indices in terms of good of country 1 this implies that both price indexes increase but given that there is a preference for homegoods the foreign price level increases more than the domestic price level and the real exchange rate appreciates.

Transport costs increase the real exchange response slightly. In the model with transport costs the real exchange rate peaks at around 0.24 percent above its steady-state value as compared to around 0.18 percent when there are no transport costs. The reason for the relatively small additional effect of adding transport costs is that there are two oppositely directed effects. First, the increase in import demand leads to an increase in transport costs and this contributes positively to the effect on the real exchange rate through the term $\widehat{p}_{2 t}$ which captures the direct effect of the trading friction. However, the effect from the preference weighted relative prices decreases relative to the same effect in a frictionless world. The reason for this is the following. The increase in domestic productivity increases both domestic and foreign imports and, as a result, transport costs rise in both countries. Hence, relative to the economy with no trading frictions, the relative price of the output good of country 2 increases more in country 1 and less in country 2. This simple insight implies that the pure preference effect is smaller in the model with transport costs than in the model with frictionless international trade ${ }^{13}$. Thus, while there is a positive direct effect on real exchange volatility of transport costs, there is also a negative indirect effect. It is also worth noticing that the real exchange rate movement is very persistent but that this is independent of the existence of transport costs.

The lower panel illustrates the same series but for a one percent increase in domestic government spending. This shock to the economy increases the relative price of domestic goods and therefore a real exchange rate depreciation. In this case the impact on the real exchange rate in the absence of transport costs is very small and the introduction of transport costs increases the impact on the real exchange rate by almost an order of magnitude. For this type of shock the direct and the indirect effect work in the same direction (since domestic transport costs increase while

\footnotetext{
${ }^{13}$ This argument rests on the assumption that the elasticity of the terms of trade to domestic (foreign) technology shocks, is bigger in this model than in the frictionless case. This is indeed the case under the baseline parameterization. Furthermore, it also rests on the assumption that the elasticity of substitution between foreign and domestic goods is greater than one. Indeed, when the elasticity of substitution is smaller than one, the two effects are equally signed.
} 
they decrease abroad). Note also that the relative importance of government spending shocks for explaining real exchange rate movements increases sharply with the introduction of transport costs.

Table 6 quantifies the real exchange rate moments and as above we decompose these into the direct transport cost effect and the preference-weighted price effect. We show only the moments from the version of the model which uses no capital in the transport sector, since the moments from the other specification are very similar. In the first row we report the moments of the real exchange rate for the economy without transport costs where preferences are the only source of real exchange rate movements. This model implies a standard deviation of the real exchange rate of 0.30 percent. This number is around 25 times lower than the typical estimate in Table 2. Thus, cross-country differences in preferences cannot by themselves account for the observed variability in real exchanges rates.

However, one surprising finding is that the model with no transport costs implies a first order autocorrelation of the real exchange rate of 0.80, a number that, if anything, is in the upper boundary of the empirical estimates. The high persistence is inherited from the persistence of the terms of trade since the real exchange rate in this model is basically a non-linear transformation of the terms of trade. This suggests that empirical tests that focus on the persistence of real exchange rates might be uninformative and that attempts to explain real exchange rate persistence with reference to imperfections in goods and asset markets might be misplaced.

The second row gives the results when transport costs are added. Transport costs increase the real exchange rate variability by around twenty percent and we find an implied standard deviation of 0.36 percent. Relative to the empirical data, the model still predicts real exchange rate variability nearly an order of magnitude below our lowest estimate for the sample of OECD countries. Notice also that the persistence of the real exchange rate decreases slightly relative to the frictionless economy. This result, which is due to the larger real exchange rate effects of government spending in the economy with transport costs, underlines our remark above: Introducing trade friction in the goods market does not automatically lead to higher real exchange rate persistence.

In the remaining rows of Table 6 we go through the same list of alternative experiments that were carried out in the previous section. The results can be summarized as follows. First, changing the steady-state size of the transport sector leaves the real exchange rate volatility unchanged. Secondly, the larger is the import share, the lower is the real exchange rate volatility. This is explained mainly by the fact that when the steady-state import share is increased, the crosscountry difference in preferences becomes smaller and thus the pure preference effect falls.

Thirdly, if the elasticity of substitution in the transport sector is very low, the model implies a substantially higher real exchange rate variability. For $1 / \mu=0.01$ we find that the model predicts a standard deviation of the real exchange rate of 1.35 percent or 4 times higher than in the baseline experiment. This estimate is still well below the median in our sample of OECD countries but goes quite a long way in closing the gap between theory and data. The Table also reveals that it is mainly the direct transport cost effect that explains the high real exchange rate variability in this parameterization. However, as discussed in the previous section, this case is unrealistic. When we instead use the value $1 / \mu=0.021$ so that we match (relative) output variabilities, the standard deviation of the real exchange rate is 0.51 percent which is around 50 percent higher than in the 
baseline parameterization but much lower than in the data.

In summary, for realistic parameter values, the international business cycle model can explain only a fraction of the observed real exchange rate volatility. Furthermore, and rather surprisingly, since the introduction of transport costs leads to a bigger role of government spending shocks, the real exchange rate is less persistent in the model with transport costs than in the model with frictionless trade.

\section{$5.1 \quad$ Measurement}

The final issue that is addressed is the measurement of the price indices. Above we used the exact consumer price indices to obtain the real exchange rate. However, national accounts statistics are usually based on fixed compositions of consumption baskets. This implies that there are differences between the measurements of the baskets of goods in our theoretical model and the national accounts measurements. In order to evaluate whether differences in measurement are important we also report moments for the real exchange rate based on the alternative consumer price indices defined by:

$$
\begin{gathered}
\widehat{Q}_{1}\left(p_{1 t}^{x}, p_{1 t}^{m}\right) \equiv\left[\lambda+(1-\lambda) \widetilde{p}_{1 t}\right] p_{1 t}^{x} \\
\widehat{Q}_{2}\left(p_{2 t}^{x}, p_{2 t}^{m}\right) \equiv\left[(1-\lambda)+\lambda \widetilde{p}_{2 t}^{-1}\right] p_{2 t}^{m}
\end{gathered}
$$

where we use the steady-state shares of domestic and foreign goods as the weights (i.e., we assume that $\lambda$ is the share of domestic goods and $(1-\lambda)$ is the share of foreign goods). This gives us the following measure of the (measurement error ridden) real exchange rate:

$$
\widehat{q}_{1 t}=\frac{\left[(1-\lambda)+\lambda \widetilde{p}_{2 t}^{-1}\right]}{\left[\lambda+(1-\lambda) \widetilde{p}_{1 t}\right]} \widehat{p}_{2 t}
$$

Clearly, since this does not allow consumers to substitute, it will lead to higher variations in the real exchange rate than (26).

The last column of Table 6 reports the moments of $\widehat{q}_{1 t}$. Measurement problems are clearly important. The results indicate that neglecting substitution leads to an almost as big increase in real exchange rate variability as does the introduction of transport costs. For the model with no trading friction, the standard deviation of $\widehat{q}_{1 t}$ is 0.35 percent as compared to 0.30 percent of $q_{1 t}$ for this specification and 0.36 percent of $q_{1 t}$ when transport costs are added. We find that relative to the moments of $q_{1 t}$ the standard deviation of $\widehat{q}_{1 t}$ is in many cases more than 30 percent higher. At the same time, however, the introduction of measurement errors does not resolve the quantitative differences between theory and data.

Thus, in summary, the difference between true consumer price indices and fixed weight indices has important implications for the behavior of the real exchange rate but cannot by itself explain why the relative price levels vary much less in the theoretical economy than in the empirical data. 


\section{Summary and Conclusions}

In this paper we have quantified the importance of transport costs in accounting for relative price behavior. In our framework, the transport sector produces the import good with inputs of foreign exports and domestic factors of production. This allows for flexible transport costs and deviates from the standard assumption of iceberg transport costs.

The first issue that we addressed was whether transport costs can help to explain what Backus, Kehoe and Kydland (1995) have phrased the "price puzzle", i.e. the high empirical terms of trade volatility relative to the theory. There are two reasons why transport costs might be important. First, such costs make trade more costly and lead to a tendency for greater relative price adjustments. Secondly, transport costs introduce a wedge between marginal rates of substitution and relative prices. We do find an increase in relative price variability but the quantitative effects are small unless the substitutability between foreign exports and domestic factor inputs in the transport sector is very low. In that case, we find that the model can be made consistent with the empirically observed variability of the terms of trade. This specification, however, also implies a counterfactually very high variability of value added in the transport sector and may be discharged on this basis.

The existence of transport costs also implies that the Law of One Price is violated and that there might be larger variation in the real exchange rate. We found that transport costs increase the variability of the real exchange rate by only around 20 percent relative to the model where real exchange rate movements are due only to cross-country preference heterogeneity. This finding is surprising in the light of the attention that transport costs have attracted in explaining deviations from PPP. Thus, contrary to popular belief, introducing transport costs does not automatically lead to much higher real exchange rate variability. Furthermore, and surprisingly, the real exchange rate persistence decreases as compared to the frictionless economy. This is because of the increased importance of more demand related shocks that by themselves lead to less persistent fluctuations in relative national price levels than technology shocks.

It would be interesting to analyze the implication of the model when other imperfections, such as imperfect competition and price rigidities, are added on top of the pure trade friction that we have analyzed. Lapham (1996) has analyzed the effects of imperfect competition and sticky prices and she found that such features might be important. Her analysis, however, is based on the presumption that there are no goods market arbitrage opportunities. Transport costs are a reason for the partial absence of goods market arbitrage and in our setting this friction varies over the business cycle. Thus, pairing the two models might give interesting new insights. Another interesting extension is to allow for an endogenous determination of the structure of trade and the cross country specialization. Transport costs can give rise to the existence of non-traded goods and shocks to the economy would lead to changes in the structure of trade and thus, presumably, to larger terms of trade variations. 


\section{$7 \quad$ References}

Armington, P., 1969, "A Theory of Demand for Products Distinguished by Place of Production", IMF Staff Papers, 27, 488-526.

Arvinitis, Athanasios V., and Anne Mikkola, 1996, "Asset Market Structure and International Trade Dynamics", American Economic Review, vol.86 no.2 (Papers and Proceedings), 67-70.

Backus, David K., Patrick J. Kehoe and Finn E. Kydland, 1992, "International Real Business Cycles", Journal of Political Economy, vol.101, 745-775.

Backus, David K., Patrick J. Kehoe and Finn E. Kydland, 1994, "Dynamics of the Trade Balance and the Terms of Trade: The J-Curve?", American Economic Review, vol.84, 84-103.

Backus, David K., Patrick J. Kehoe and Finn E. Kydland, 1995, "International Business Cycles: Theory and Evidence", Chapter 11 in Thomas F. Cooley (ed.), Frontiers of Business Cycle Research, Princeton, New Jersey: Princeton University Press.

Ceglowski, J., 1994, "The Law of One Price Revisited - New Evidence on the Behaviour of International Prices", Economic Inquiry, vol.32, no.3, 407-18.

Crucini, Mario J., 1997, "International Comovement: Is Theory Really Ahead of International Business Cycle Measurement?", manuscipt, Ohio State University.

Cumby, Robert E., and Maurice Obstfeld, 1984, "International Interest Rates and Price Level Linkages under Flexible Exchange Rates: A Review of Recent Evidence", in John F.O. Bilson and Richard C. Marston (eds.), Exchange Rate Theory and Practice, Chicago: Chicago University Press.

Devereux, Michael B., 1997, "Real Exchange Rates and Macroeconomics: Evidence and Theory", Canadian Journal of Economics, vol.30, no.4A, 773-808.

Dumas, Bernard, 1992, "Dynamic Equilibrium and the Real Exchange Rate in a Spatially Separated World", Review of Financial Studies, vol.5 no.2, 153-80.

Engel, Charles, 1993, "Real Exchange Rates and Relative Prices: An Empirical Investigation", Journal of Monetary Economics, vol.32, 35-50.

Engel, Charles, and J.H. Rogers, 1996, "How Wide is the Border?", American Economic Review, vol.86, no.5, 1112-25.

Feenstra, Robert C., 1989, "Symmetric Pass-Through of Tariffs and Exchange Rates under Imperfect Competition: An Empirical Test", Journal of International Economics, vol.27, no.1-2, $25-45$.

Frenkel, Jacob A., 1981, "The Collapse of Purchasing Power Parities During the 1970's", European Economic Review, vol.16, 145-65.

Froot, Kenneth A., and Kenneth Rogoff, 1995, "Perspectives on Purchasing Power Parity and Long-Run Real Exchange Rates", in: Gene M. Grossman and Kenneth Rogoff (eds.), Handbook of International Economics, vol.3, Amsterdam: North-Holland Publishers.

Genberg, Hans, 1978, "Purchasing Power Parity under Fixed and Flexible Exchange Rates", Journal of International Economics, vol.8 (May), 237-76. 
Goldberg, P.K., and Michael M. Knetter, 1997, "Goods Prices and Exchange Rates: What Have We Learned?", Journal of Economic Literature, vol.35, no.3, 1243-72.

Isard, Peter, 1977, "How Far Can We Push "The Law of One Price"?", American Economic Review, vol.67 (December), 942-48.

Kravis, Irving B., and Robert E. Lipsey, 1978, "Price Behaviour in the Light of Balance of Payments Theories", Journal of International Economics, vol.8 (May), 193-246.

Krugman, Paul R., and Maurice Obstfeld, 1991, "International Economics: Theory and Policy", 2.nd Edition, New York: Harper Collins.

Krugman, Paul R., and Anthony J. Venables, 1995, "Globalization and the Inequality of Nations", Quarterly Journal of Economics, vol.110, no.4, 857-80.

Lapham, Beverly J., 1995, "A Dynamic General Equilibrium Analysis of Deviations from the Law of One Price", Journal of Economic Dynamics and Control, vol.19, no.8, 1355-1389.

McCloskey, Donald M., and J. Richard Zecher, 1984, "The Success of PPP", in M.D. Bordo and A.J. Schwartz (eds.), A Retrospective on the Classical Gold Standard, 1821-1931, Chicago: Chicago University Press.

Michael, Panos, A. Robert Nobay, and David A. Peel, 1997, "Transactions Costs and Nonlinear Adjustments in Real Exchange Rates: An Empirical Investigation", Journal of Political Economy, Vol.105 (4), 862-79.

Obstfeld, Maurice, and Kenneth Rogoff, 1996. "Foundations of International Macroeconomics". MIT Press.

Ravn, Morten O., 1997, "International Business Cycles in Theory and in Practise", Journal of International Money and Finance, vol. 16, no.2, 255-83.

Ravn, Morten O. and Harald Uhlig, 1997, "On Adjusting the HP-Filter for the Frequency of Observations", CentER Discussion Paper no.9750.

Rogoff, Kenneth, 1996, "The Purchasing Power Parity", Journal of Economic Literature, vol.34, no.2, 647-68.

Venables, Anthony J., 1996, "Equilibrium Locations of Vertically Linked Industries", International Economic Review, vol.37, no.2, 341-59. 


\section{Appendix: Steady State Analysis}

In this Appendix we will show how the steady state of the economy is derived. We compute the competitive equilibrium using the Negishi-Mantel algorithm from the social planners problem. Given welfare weights $\Omega_{i}$ the social planner solves the following problem:

$$
\max \Omega_{1} U_{1 t}+\Omega_{2} U_{2 t}
$$

subject to:

$$
\begin{gathered}
z_{j t}\left(k_{j t}^{y}\right)^{1-\alpha}\left(n_{j t}^{y}\right)^{\alpha}=d_{j t}+x_{j t} \\
c_{j t}+g_{j t}+i_{j t}^{y}+i_{j t}^{c y}+\phi^{y}\left(i_{j t}^{y}, k_{j t}^{y}\right)+\phi^{t r}\left(i_{j t}^{t r}, k_{j t}^{t r}\right) \\
=\left[\omega_{1} d_{j t}^{1-\rho}+\omega_{2}\left[\pi_{1} x_{\neq j t}^{1-\mu}+\pi_{2}\left\{\left(k_{j t}^{t r}\right)^{1-\gamma}\left(n_{j t}^{t r}\right)^{\gamma}\right\}^{1-\mu}\right]^{(1-\rho) /(1-\mu)}\right]^{1 /(1-\rho)} \\
k_{j t+1}^{y}=\left(1-\delta_{y}\right) k_{j t}^{y}+i_{j t}^{y} \\
k_{j t+1}^{t r}=\left(1-\delta_{t r}\right) k_{j t}^{t r}+i_{j t}^{t r}
\end{gathered}
$$

taking the processes for technology and government spending for exogenous.

The first-order necessary conditions can be written as:

$$
\begin{gathered}
\Omega_{j} \theta c_{j t}^{\theta(1-\sigma)-1}\left(1-n_{j t}^{y}-n_{j t}^{t r}\right)^{(1-\theta)(1-\sigma)}=\lambda_{j t} \\
\Omega_{j}(1-\theta) c_{j t}^{\theta(1-\sigma)}\left(1-n_{j t}^{y}-n_{j t}^{t r}\right)^{(1-\theta)(1-\sigma)-1}=\chi_{j t} \alpha y_{j t} / n_{j t}^{y} \\
\Omega_{j}(1-\theta) c_{j t}^{\theta(1-\sigma)}\left(1-n_{j t}^{y}-n_{j t}^{t r}\right)^{(1-\theta)(1-\sigma)-1} \\
=\lambda_{j t} V_{j t}^{\rho} \omega_{2} m_{j t}^{\mu-\rho} \pi_{2} \gamma\left(\left(n_{j t}^{t r}\right)^{\gamma}\left(k_{j t}^{t r}\right)^{1-\gamma}\right)^{1-\mu} / n_{j t}^{t r} \\
\chi_{j t}=\lambda_{j t} V_{j t}^{\rho} \omega_{1} d_{j t}^{-\rho} \\
\chi_{j t}=\lambda_{\neq j t} V_{\neq j t}^{\rho} \omega_{2} m_{\neq j t}^{\mu-1} \pi_{1} x_{j t}^{-\mu} \\
\lambda_{j t}\left(1+\frac{\partial \phi^{y}\left(i_{j t}^{y}, k_{j t}^{y}\right)}{\partial i_{j t}^{y}}\right)=\varphi_{j t}^{y} \\
\lambda_{j t}\left(1+\frac{\partial \phi^{t r}\left(i_{j t}^{t r}, k_{j t}^{t r}\right)}{\partial i_{j t}^{t r}}\right)=\varphi_{j t}^{t r}
\end{gathered}
$$




$$
\begin{gathered}
\varphi_{j t}^{y}=E_{t} \beta\left[\varphi_{j t+1}^{y}\left(1-\delta^{y}\right)+\chi_{j t+1}(1-\alpha) y_{j t+1} / k_{j t+1}^{y}-\lambda_{j t+1} \frac{\partial \phi^{y}\left(i_{j t+1}^{y}, k_{j t+1}^{y}\right)}{\partial k_{j t+1}^{y}}\right] \\
\varphi_{j t}^{t r}=E_{t} \beta\left\{\varphi_{j t+1}^{t r}\left(1-\delta^{t r}\right)-\lambda_{j t+1} \frac{\partial \phi^{t r}\left(i_{j t+1}^{t r}, k_{j t+1}^{t r}\right)}{\partial k_{j t+1}^{t r}}+\right. \\
\left.\lambda_{j t+1} V_{j t+1}^{\rho} \omega_{2} m_{j t+1}^{\mu-\rho} \pi_{2}(1-\gamma) \frac{\left(\left(n_{j t+1}^{t r}\right)^{\gamma}\left(k_{j t+1}^{t r}\right)^{1-\gamma}\right)^{1-\mu}}{k_{t+1}^{t r}}\right\}
\end{gathered}
$$

where $\lambda_{j t}$ is the Lagrange multiplier on (3), $\chi_{j t}$ is the multiplier associated with (31), $\varphi_{t}^{y}$ is the multiplier on (33), and $\varphi_{t}^{t r}$ the multiplier on (34).

To derive the steady state of the economy we impose the following conditions. First, we assume that the two countries have identical steady states (this implies that $\Omega_{1}=\Omega_{2}$ which we normalize to unity). Secondly, we assume that along the steady state path $V_{j}=y_{j}$. Thirdly, we assume that imports equal exports along the steady state path $\left(m_{j}=x_{\neq j}\right)$. Finally, we assume that there are no capital adjustment costs along the steady state path.

Using the symmetry assumption, combining (38) and (39), and using that $d_{j}=\left(1-M_{s}\right) y_{j}, x_{j}=M_{s} y_{j}$, and that $V_{j}=y_{j}$, we get that:

$$
\omega_{1}=\frac{\pi_{1}\left(1-M_{s}\right)^{\rho}}{\pi_{1}\left(1-M_{s}\right)+M_{s}}, \omega_{2}=\frac{M_{s}^{\rho}}{\pi_{1}\left(1-M_{s}\right)+M_{s}}
$$

Next, from the condition that $m_{j}=x_{\neq j}$ we get the restriction that:

$$
\left(1-\pi_{1}\right) m_{j}^{1-\mu}=\pi_{2}\left(\left(n_{j}^{t r}\right)^{\gamma}\left(k_{j}^{t r}\right)^{1-\gamma}\right)^{1-\mu}
$$

Combining (36) and (37), using (39), symmetry, and (45) gives us that:

$$
\pi_{1}=\frac{\gamma M_{s}}{\gamma M_{s}+\alpha n_{j}^{t r} / n_{j}^{y}}
$$

From (35) and (36), and $\chi_{j} / \lambda_{j}=\omega_{1}\left(1-M_{s}\right)^{-\rho}$ (from to (38)) we get that:

$$
\theta=\frac{s_{c}\left(1-M_{s}\right)^{\rho} n_{j}^{y}}{s_{c}\left(1-M_{s}\right)^{\rho} n_{j}^{y}+\alpha \omega_{1}\left(1-n_{j}^{y}-n_{j}^{t r}\right)}
$$

Using the assumption of absence of capital adjustment costs along the steady state path, it follows from (40) and (41) that $\varphi_{j}^{y}=\varphi_{j}^{t r}=\lambda_{j}$. Evaluating (42) along the steady state path, then delivers:

$$
\frac{k^{y}}{y}=\frac{\beta(1-\alpha) \omega_{1}\left(1-M_{s}\right)^{-\rho}}{1-\beta\left(1-\delta^{y}\right)}
$$

Finally, evaluating (43) along the steady state path and using (48) gives us:

$$
\frac{k_{j}^{t r}}{k_{j}^{y}}=M_{s}\left(\frac{1-M_{s}}{M_{s}}\right)^{\rho} \frac{1-\gamma}{1-\alpha} \frac{\omega_{2}}{\omega_{1}}\left(1-\pi_{1}\right)
$$




\section{$9 \quad$ Tables and Figures}

Table 1. Moments of Terms of Trade and Real Exchange Rates

\begin{tabular}{||l|rrrrrr|rrrr||}
\hline \hline & \multicolumn{5}{|c|}{ Terms of Trade } & \multicolumn{4}{c||}{ Real Exchange Rates } \\
\hline & $s(t t)$ & $s(y)$ & $s(n x)$ & $a u(t t)$ & $c(t t, y)$ & $c(t t, n x)$ & $s\left(p^{1}\right)$ & $a u\left(p^{1}\right)$ & $s\left(p^{2}\right)$ & $a u\left(p^{2}\right)$ \\
\hline AUS & 6.24 & 1.47 & 1.12 & 0.76 & -0.17 & 0.09 & 5.72 & 0.71 & 9.32 & 0.76 \\
CAN & 2.92 & 1.68 & 0.76 & 0.86 & -0.14 & -0.03 & 2.76 & 0.85 & 9.84 & 0.81 \\
FRA & 3.42 & 0.98 & 0.84 & 0.75 & -0.19 & -0.49 & 8.59 & 0.80 & 3.59 & 0.76 \\
GER & 2.61 & 1.49 & 0.77 & 0.82 & -0.06 & -0.06 & 8.69 & 0.76 & - & - \\
ITA & 3.36 & 1.68 & 1.24 & 0.74 & 0.40 & -0.68 & 7.86 & 0.79 & 3.66 & 0.45 \\
JAP & 6.98 & 1.31 & 0.93 & 0.87 & -0.21 & -0.55 & 8.92 & 0.81 & 6.61 & 0.73 \\
SWI & 2.76 & 1.91 & 1.30 & 0.89 & 0.41 & -0.60 & 9.26 & 0.74 & 3.63 & 0.60 \\
UK & 3.04 & 1.77 & 1.22 & 0.80 & 0.11 & -0.57 & 8.29 & 0.81 & 6.42 & 0.75 \\
US & 3.44 & 1.84 & 0.48 & 0.81 & -0.17 & 0.15 & - & - & 8.69 & 0.76 \\
\hline \hline
\end{tabular}

Data source: OECD national accounts. The sample period is 1970-1992 and the data are quarterly. Terms of trade $(t t)$ are computed as the implicit imports deflator divided by the implicit exports deflator, and net exports $(n x)$ as exports minus imports divided by output, all in current prices. The real exchange rate $p^{1}$ is defined against the US defined as the nominal exchange rate times the ratio of implicit consumption deflators. $p^{2}$ is defined equivalently against Germany. All data are detrended using the Hodrick-Prescott filter. s(x) denotes the standard deviation of $\mathrm{x}, \mathrm{au}(\mathrm{x})$ the first-order autocorrelation, and $\mathrm{c}(\mathrm{x}, \mathrm{y})$ is the correlation of $\mathrm{x}$ and $\mathrm{y} . \mathrm{y}$ denotes real GDP.

Table 2. Sectorial Data.

\begin{tabular}{|c|c|c|c|c|c|c|c|}
\hline & \multicolumn{5}{|c|}{ Mean } & \multicolumn{2}{|c|}{ Std. Deviation } \\
\hline country & $\frac{y^{t r s}}{y}(\%)$ & $\frac{k^{\text {trs }}}{k}(\%)$ & $\frac{E^{t r s}}{E}(\%)$ & $\left(\frac{k}{y}\right)^{t r s}$ & $\left(\frac{k}{y}\right)$ & $s(\widehat{y})$ & $s\left(\widehat{y}^{t r}\right)$ \\
\hline Australia & 6.6 & 8.4 & 7.6 & 4.9 & 3.8 & 1.17 & 1.50 \\
\hline Belgium & 8.4 & 7.8 & - & 3.4 & 3.6 & 1.15 & 3.20 \\
\hline Canada & 6.1 & 9.3 & 7.4 & 5.0 & 3.5 & 1.47 & 1.96 \\
\hline Denmark & 8.5 & 11.0 & 7.0 & 6.3 & 4.7 & 1.23 & 2.94 \\
\hline Finland & 7.6 & 7.5 & 6.9 & 5.4 & 5.5 & 1.50 & 2.25 \\
\hline Germany & 5.7 & 7.5 & 5.7 & 5.3 & 4.1 & 1.43 & 1.86 \\
\hline Great Br. & 6.9 & 10.5 & 6.2 & 5.3 & 3.5 & 1.48 & 1.83 \\
\hline Japan & 6.4 & 3.3 & 5.7 & 1.4 & 2.8 & 1.77 & 1.89 \\
\hline Norway & 10.7 & 24.7 & 10.4 & 10.6 & 4.5 & 1.44 & 2.28 \\
\hline Sweden & 6.3 & 8.3 & 7.1 & 5.9 & 4.5 & 1.01 & 2.83 \\
\hline USA & 5.8 & 6.8 & 4.4 & 5.2 & 4.2 & 1.66 & 2.35 \\
\hline Mean & 7.2 & 9.6 & 6.8 & 5.2 & 4.1 & 1.39 & 2.26 \\
\hline
\end{tabular}

Source: The OECD Intersectorial Data Base. Observations are annual. Sample periods: Australia 1969-85, Belgium 1970-85, Canada 1961-85, Germany and Finland 1960-85, Denmark 1966-85, Great Britain 1973-86, Italy and the Netherlands 1970-85, Japan 1970-86, Norway 1962-86, Sweden 1970-86, US 1960-86. Superscript "trs" denotes transport sector variables; variables without superscripts are aggregate economy variables. $\mathrm{y}$ is real GDP, $\mathrm{k} / \mathrm{y}$ is the capital-output ratio, and $\mathrm{E}$ is employment. $\mathrm{s}(\mathrm{y})\left(\mathrm{s}\left(\mathrm{y}^{\text {trs }}\right)\right)$ is the percentage standard deviation of HP-filtered total output (transport sector output). 
Table 3. Calibration

\begin{tabular}{||llll||}
\hline \hline \multicolumn{3}{||l||}{ Common Parameters (baseline parameterization) } & \\
\hline$\frac{n^{y}+n^{t r}}{T}=0.30$ & $\theta=0.267$ & $\beta=0.99$ & $\sigma=2$ \\
$\omega_{1}=0.796$ & $\omega_{2}=0.446$ & $1 / \rho=1.5$ & $m_{s}=0.2$ \\
$n^{t r} / n^{y}=0.073$ & $\alpha=0.64$ & $1 / \mu=0.1$ & $\delta=0.025$ \\
$s_{g}=0.20$ & $\kappa_{g}=0.95$ & $\sigma_{v}=0.02$ & $\operatorname{cor}\left(v_{1}, v_{2}\right)=0$ \\
$\kappa_{1}=0.906$ & $\kappa_{2}=0.088$ & $\sigma_{\epsilon}=0.0852$ & $\operatorname{cor}\left(\epsilon_{1}, \epsilon_{2}\right)=0.25$ \\
\hline Table 4s and $\mathbf{6 :} \gamma=1$ & & Row $(6)$ \\
\hline Row $(3)$ & Row $(4)$ & Row $(5)$ & $1 / \mu=0.01$ \\
$\sigma_{v}=0$ & $n^{t r} / n^{y}=0.036$ & $n^{t r} / n^{y}=0.116$ & \\
Row $(7)$ & Row $(8)$ & & Row $(6)$ \\
$m_{s}=0.3$ & $1 / \rho=0.5$ & & $1 / \mu=0.01$ \\
\hline Table 5: $\gamma=0.57, k^{y} / k^{t r}=0.098$ & \\
\hline Row $(3)$ & Row $(4)$ & Row $(5)$ & \\
$\sigma_{v}=0$ & $n^{t r} / n^{y}=0.036$ & $n^{t r} / n^{y}=0.116$ & \\
Row $(7)$ & Row $(8)$ & Row $(9)$ & \\
$1 / \mu=0.021$ & $m_{s}=0.3$ & $1 / \rho=0.5$ & \\
\hline \hline
\end{tabular}

Table 4. Moments of the Economy with Labor Only in Transports

\begin{tabular}{||l|llllll||}
\hline \hline \multirow{2}{*}{ Parameterization } & \multicolumn{5}{|c||}{ Moment } \\
\cline { 2 - 7 } & $s(y)$ & $s(p)$ & $s(n x / y)$ & $a u(p)$ & $c o r(p, y)$ & $c o r(p, n x / y)$ \\
\hline Costs & 1.29 & 0.59 & 0.47 & 0.80 & 0.47 & -0.12 \\
$(2)$ Baseline & $(0.17)$ & $(0.08)$ & $(0.06)$ & $(0.05)$ & $(0.14)$ & $(0.13)$ \\
& 1.25 & 0.65 & 0.38 & 0.78 & 0.46 & -0.19 \\
(3) Only Technology & $(0.16)$ & $(0.09)$ & $(0.05)$ & $(0.06)$ & $(0.14)$ & $(0.14)$ \\
Shocks & 1.24 & 0.57 & 0.34 & 0.81 & 0.56 & -0.50 \\
(4) Realistic Transport & $(0.16)$ & $(0.09)$ & $(0.04)$ & $(0.05)$ & $(0.12)$ & $(0.06)$ \\
Sector & 1.27 & 0.62 & 0.42 & 0.79 & 0.47 & -0.16 \\
(5) Large Transport & $(0.16)$ & $(0.09)$ & $(0.05)$ & $(0.06)$ & $(0.14)$ & $(0.13)$ \\
Sector & 1.23 & 0.67 & 0.34 & 0.77 & 0.47 & -0.22 \\
(6) Low Transport & $(0.16)$ & $(0.09)$ & $(0.04)$ & $(0.06)$ & $(0.14)$ & $(0.14)$ \\
Sector Elasticity & 1.27 & 1.57 & 0.57 & 0.68 & 0.02 & -0.75 \\
(7) Matching Transp. & $(0.16)$ & $(0.20)$ & $(0.08)$ & $(0.07)$ & $(0.17)$ & $(0.07)$ \\
Sector Variability & 1.25 & 0.79 & 0.42 & 0.73 & 0.36 & -0.40 \\
(8) Large Import & $(0.16)$ & $(0.10)$ & $(0.05)$ & $(0.06)$ & $(0.15)$ & $(0.12)$ \\
Share & 1.23 & 0.72 & 0.69 & 0.79 & 0.55 & -0.33 \\
(9) Small Armington & $(0.16)$ & $(0.10)$ & $(0.08)$ & $(0.05)$ & $(0.13)$ & $(0.11)$ \\
Elasticity & 1.17 & 1.08 & 0.46 & 0.74 & 0.44 & -0.66 \\
\hline \hline
\end{tabular}

Note: Numbers in parentheses are standard deviations of the moments. The numbers are average moments of HP-filtered variables computed from 100 simulations of the model each for a length of 100 periods. 
Table 5. Moments From the General Model

\begin{tabular}{||l|llllll||}
\hline \hline \multirow{2}{*}{ Parameterization } & \multicolumn{5}{|c||}{ Moment } \\
\cline { 2 - 7 } (1) No Transport & $s(y)$ & $s(p)$ & $s(n x / y)$ & $a u(p)$ & $\operatorname{cor}(p, y)$ & $\operatorname{cor}(p, n x / y)$ \\
Costs & 1.29 & 0.59 & 0.47 & 0.80 & 0.47 & -0.12 \\
$(2)$ Baseline & $(0.17)$ & $(0.08)$ & $(0.06)$ & $(0.05)$ & $(0.14)$ & $(0.13)$ \\
& 1.24 & 0.71 & 0.24 & 0.72 & 0.47 & -0.31 \\
(3) Only Technology & $(0.15)$ & $(0.12)$ & $(0.03)$ & $(0.08)$ & $(0.14)$ & $(0.12)$ \\
Shocks & 1.22 & 0.62 & 0.21 & 0.73 & 0.60 & -0.71 \\
(4) Realistic Transport & $(0.16)$ & $(0.11)$ & $(0.03)$ & $(0.07)$ & $(0.11)$ & $(0.06)$ \\
Sector & 1.27 & 0.66 & 0.30 & 0.74 & 0.47 & -0.23 \\
(5) Large Transport & $(0.16)$ & $(0.11)$ & $(0.04)$ & $(0.07)$ & $(0.14)$ & $(0.11)$ \\
Sector & 1.21 & 0.76 & 0.20 & 0.71 & 0.46 & -0.39 \\
(6) Low Transport & $(0.15)$ & $(0.12)$ & $(0.03)$ & $(0.08)$ & $(0.14)$ & $(0.12)$ \\
Sector Elasticity & 1.20 & 0.80 & 0.26 & 0.70 & 0.62 & -0.51 \\
(7) Large Import & $(0.15)$ & $(0.13)$ & $(0.03)$ & $(0.08)$ & $(0.11)$ & $(0.10)$ \\
Share & 1.22 & 0.76 & 0.40 & 0.71 & 0.53 & -0.47 \\
(8) Small Armington & $(0.15)$ & $(0.12)$ & $(0.05)$ & $(0.08)$ & $(0.12)$ & $(0.10)$ \\
Elasticity & 1.19 & 1.13 & 0.39 & 0.69 & 0.42 & -0.75 \\
\hline \hline
\end{tabular}

See notes to Table 4.

Table 6. Moments of Real Exchange Rates

\begin{tabular}{||l|lllll||}
\hline \hline \multirow{3}{*}{ Parameterization } & \multicolumn{5}{|c||}{ Moment } \\
\cline { 2 - 6 } & $s\left(\widehat{p}_{2}\right)$ & $s\left(q_{1} / \widehat{p}_{2}\right)$ & $s\left(q_{1}\right)$ & $a u\left(q_{1}\right)$ & $s\left(q_{1}^{\text {fix }}\right)$ \\
\hline Costs & 0 & 0.30 & 0.30 & 0.80 & 0.35 \\
(2) Baseline Model & 0 & $(0.05)$ & $(0.05)$ & $(0.06)$ & $(0.05)$ \\
& 0.32 & 0.17 & 0.36 & 0.79 & 0.50 \\
(3) Only Technology & $(0.04)$ & $(0.02)$ & $(0.05)$ & $(0.05)$ & $(0.07)$ \\
Shocks & 0.31 & 0.17 & 0.31 & 0.83 & 0.44 \\
(4) Realistic Transport & $(0.04)$ & $(0.02)$ & $(0.05)$ & $(0.05)$ & $(0.07)$ \\
Sector & 0.17 & 0.09 & 0.36 & 0.79 & 0.43 \\
(5) Large Transport & $(0.02)$ & $(0.01)$ & $(0.05)$ & $(0.05)$ & $(0.06)$ \\
Sector & 0.44 & 0.24 & 0.36 & 0.79 & 0.57 \\
(6) Low Transport & $(0.05)$ & $(0.03)$ & $(0.05)$ & $(0.06)$ & $(0.08)$ \\
Sector Elasticity & 0.36 & 1.28 & 1.35 & 0.66 & 1.43 \\
(7) Matching Transp. & $(0.04)$ & $(0.16)$ & $(0.19)$ & $(0.07)$ & $(0.19)$ \\
Sector Variability & 0.33 & 0.37 & 0.51 & 0.73 & 0.64 \\
(8) Large Import & $(0.04)$ & $(0.05)$ & $(0.07)$ & $(0.06)$ & $(0.09)$ \\
Share & 0.22 & 0.12 & 0.26 & 0.81 & 0.37 \\
(9) Small Armington & $(0.03)$ & $(0.01)$ & $(0.04)$ & $(0.05)$ & $(0.05)$ \\
Elasticity & 0.32 & 0.20 & 0.62 & 0.75 & 0.84 \\
\hline \hline
\end{tabular}


Figure 1. Impulse Responses
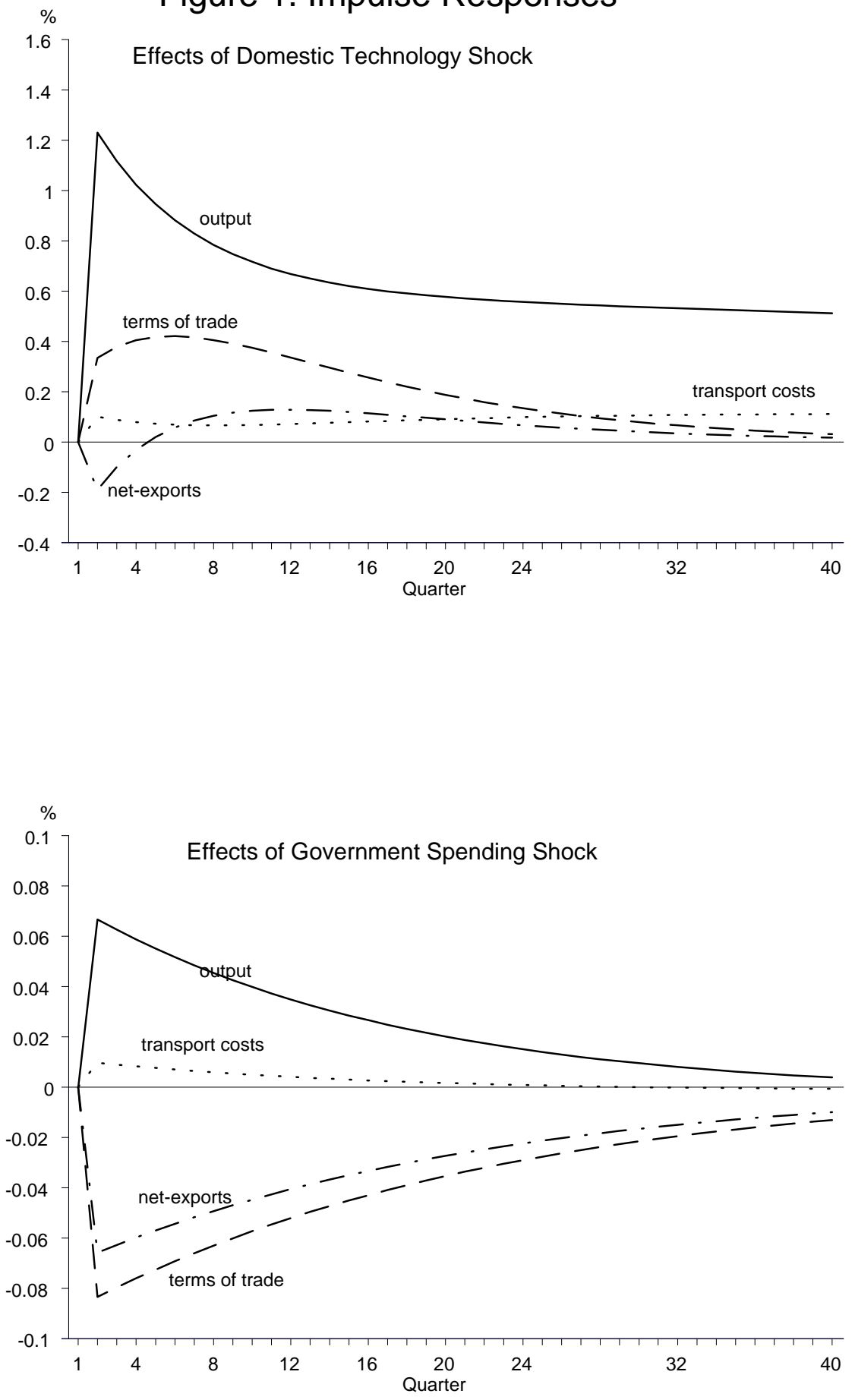
Figure 2.
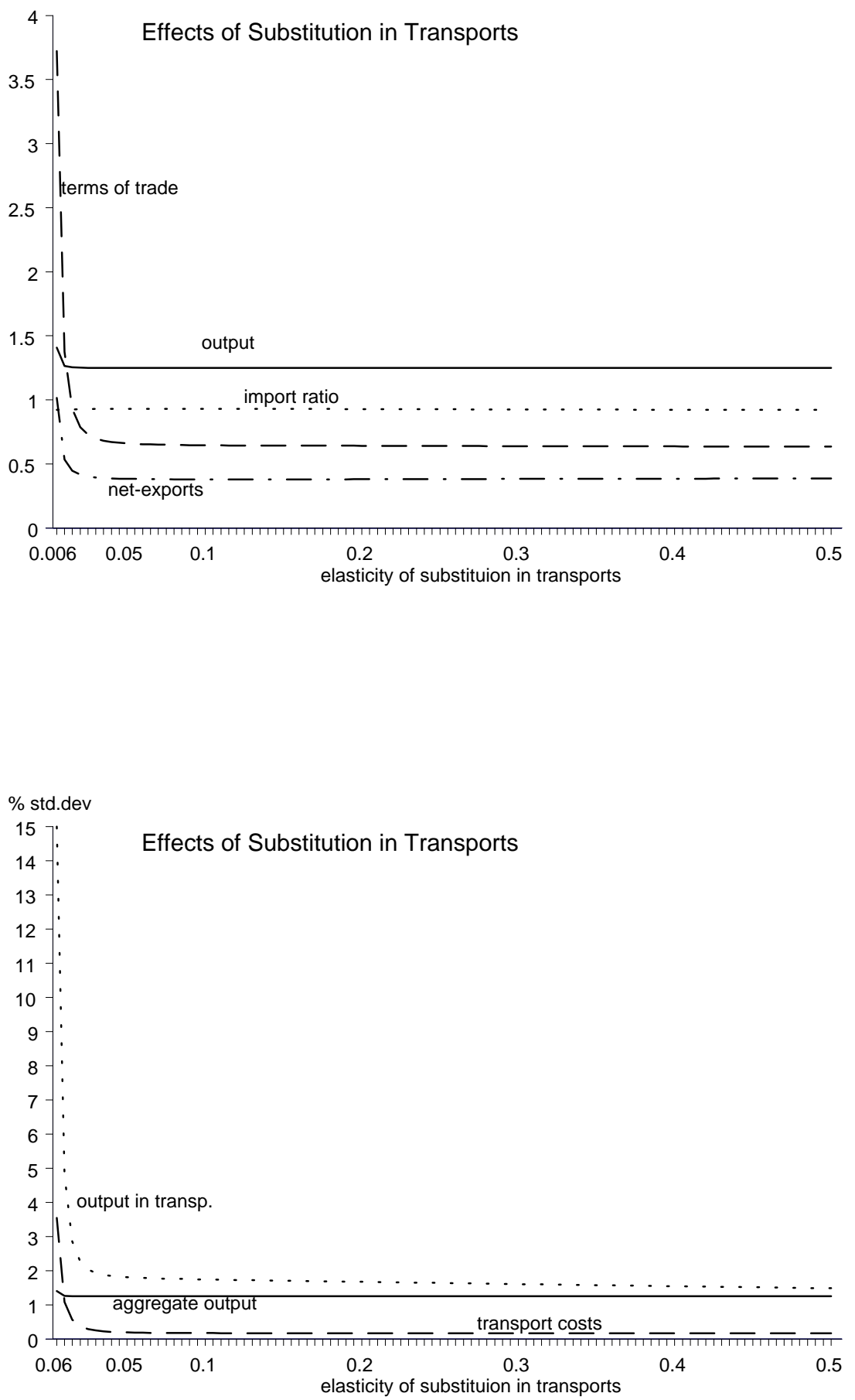
Figure 3. Importance of Capital Share

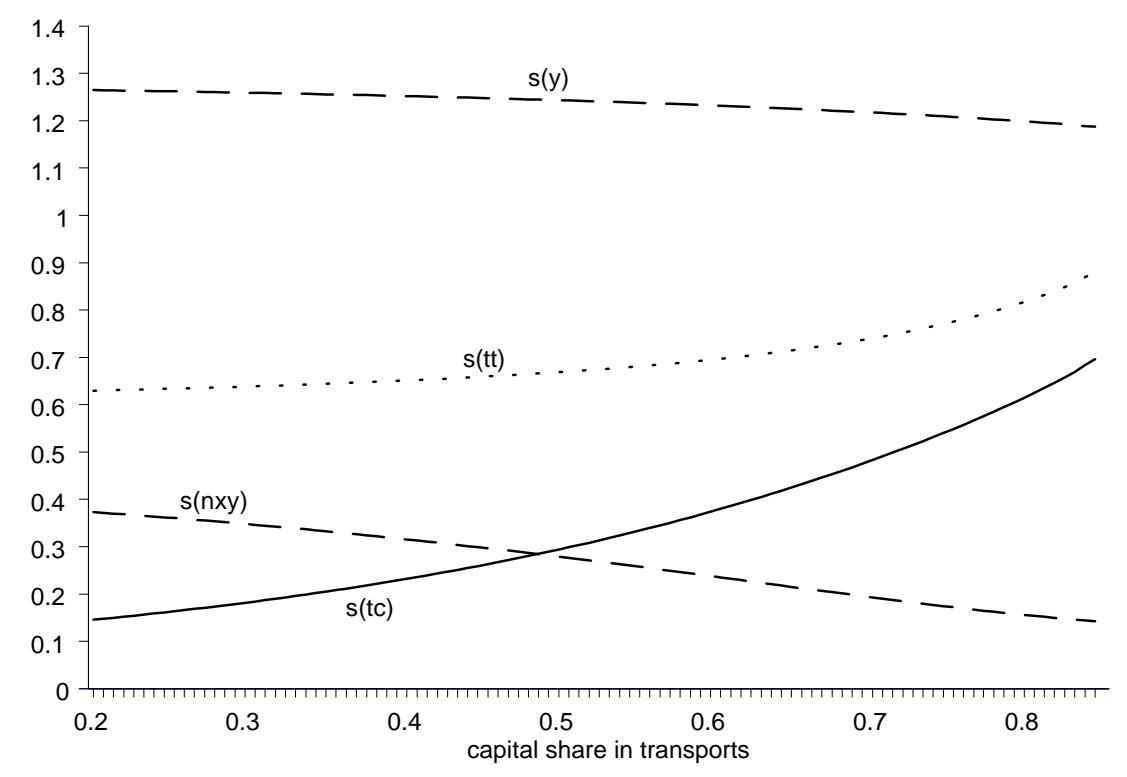

Figure 4. Real Exchange Rate Dynamics

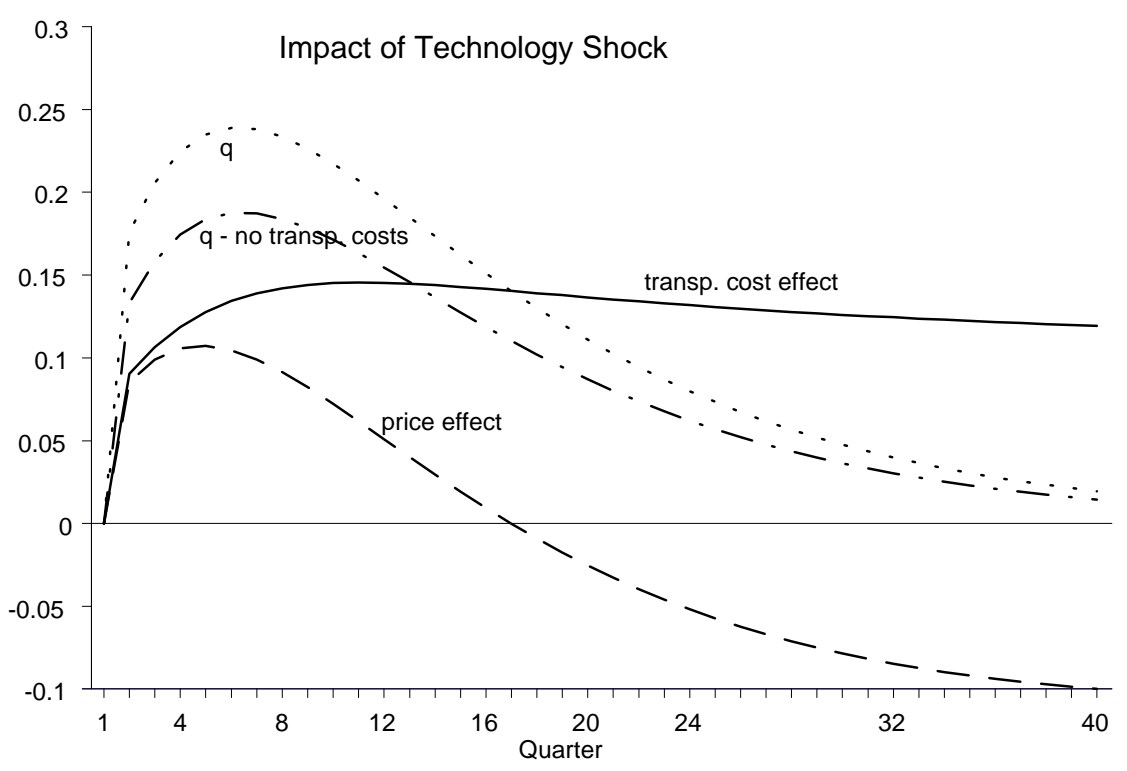




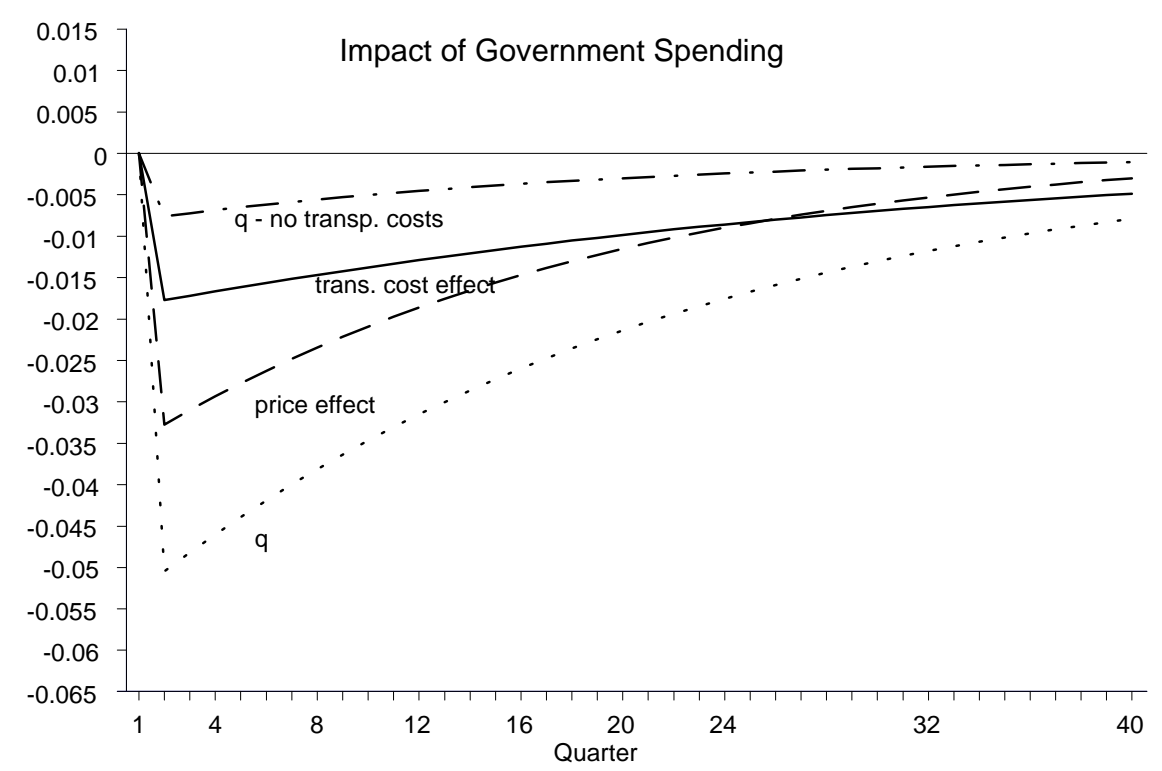

